\title{
Frequency of Helicobacter Pylori in Patients with Dyspepsia in Civil Hospital, Khairpur
}

\author{
SHEHZAD TARIQ ${ }^{1}$, FARUKH IMTIAZ², BAKHTIAR AHMED ${ }^{3}$, SARMAD SAEED ${ }^{4}$, INAM ALI LARIK ${ }^{5}$, M. ASHRAF SIAL ${ }^{6}$ \\ ${ }^{1}$ Lecturer, Department of Community Medicine, Khairpur Medical College, Khairpur Mir's \\ ${ }^{2}$ Assistant professor, Department of Community Medicine, Khairpur Medical College, Khairpur Mir's \\ ${ }^{3}$ Associate Professor, Department of Paediatric Medicine Gambat Medical College, Khairpur Mir's \\ ${ }^{4}$ Medical Officer, Department of Medicine, Khairpur Medical College/Civil Hospital, Khairpur Mir's \\ ${ }^{5}$ Lecturer, Department of Microbiology, Govt. Superior Science College, Khairpur Mir's \\ ${ }^{6}$ Lecturer, Department of Microbiology, Govt. Degree College, Bozdar Wada, Khairpur Mir's \\ Correspondence to Dr Shehzad Tariq; doc.tariq110@gmail.com, Cell: +92 03332693675
}

\begin{abstract}
Background: The Helicobacter pylori is a gram negative bacterium which is found in majority of population in all over the world. It is possible due to contaminated food consumption, working in unsanitary condition and the use of public toilets with poor sanitation. In the field of gastroenterology infection caused by $\mathrm{H}$. pylori and functional dyspepsia are most common clinical issue but their association is also unclear.

Aim: To determine the frequency of Helicobacter Pylori in patients with presenting with Dyspepsia in Civil Hospital, Khairpur

Study Design: Descriptive Cross sectional study.

Duration of study: One year from 01-Jan-

2019 to $31-12-2019$.

Setting: Institute of Microbiology, Shah Abdul Latif University, Khairpur.

Methodology: All the patients between 15 to 60 years of age, admitted patients of dyspepsia were diagnosed and evaluated for Helicobacter pylori infection through histopathological examination.

Results: Total 100 subjects with dyspepsia were screened for Helicobacter pylori infection. Mean age of patients was $40.0 \pm 15.40$. Majority of patients with $H$. pylori positive were from age group between $40-60$ years, from which $56.7 \%$ of them were $H$. pylori positive; while $30 \%$ of patients were from age between $20-40$ years of age and only $13.3 \%$ were from age below 20 years of age

Conclusion: The dyspeptic patients are prone to acquire Helicobacter pylori infection therefore present study reported 30\% prevalence for $H$. pylori infection with male gender predominance.

Key words: Dyspepsia, Helicobacter Pylori Infection, Peptic ulcer, histopathology, endoscopy
\end{abstract}

\section{INTRODUCTION}

A Gram-negative bacterium of the stomach, Helicobacter pylori is found in approximately half of the world's population ${ }^{1}$. The infection is mostly acquired earlier in life and is common in less developed countries ${ }^{2}$. In Some patients $H$. pylori infected patients remain asymptomatic for a long time due to superficial infection and usually symptoms appear when organism damages the duodenum or lining of stomach ${ }^{3}$. H. pylori infection may lead to number of gastric disease like gastritis, peptic ulcer disease and gastric carcinoma ${ }^{4,5}$.

$H$. pylori have been classified by World Health Organization as risk for gastric adeno-carcinoma and class I carcinogen 6 . In previous Epidemiological studies ${ }^{7}$ it was reported that $H$. pylori is responsible for up to $90 \%$ of gastric cancers and its incidence can be reduced to a significant level by giving standard eradication therapy ${ }^{8}$. In the field of gastroenterology infection caused by $\mathrm{H}$. pylori and functional dyspepsia are most common clinical issue but their association is unclear still under debate ${ }^{8}$. In previous literature prevalence rate of $H$. pylori in functional dyspepsia was reported upto $87 \%$ but their association and role in appearance of symptoms was not observed.

Previous trials shown that non ulcer dyspepsia can be managed with eradication of $H$. pylori but these findings were conflicting, but few studies observed subsiding of symptoms when eradication therapy of $H$. pylori was given ${ }^{9}$, 10. Hence, this study is carried out to determine the frequency of $H$. pylori in dyspeptic patients so that early and effective measures and management can be provided and study will be helpful for streamline referral of patients to specialized treatment before appearance of life threatening complication of $H$. pylori infection.

\section{METHODOLOGY}

Study was cross sectional in design and conducted in Institute of Microbiology, Shah Abdul Latif University, Khairpur, from 01-Jan-2019 to 31-12-2019 in one year duration. Study was started after ethical approval from hospital ethical committee. Written informed consent was obtained from patients after detailed information about purpose of study. Patients of both gender (male or female), age from 15 years to 60 years and presenting with upper abdominal pain and signs of dyspepsia were included in the study. Sample size was calculated by using openepi.com an online sample size calculator using $\mathrm{H}$. pylori prevalence in functional dyspepsia as $64.4 \% \%$ with $10 \%$ margin of error, 95\% confidence level. Endoscopy was performed to collect samples, on patients admitted to gastroenteritis wards with acute or chronic gastritis and peptic ulcer problem. It was performed vialignocaine throat anesthesia and with the administration of intra-venous diazepam. Samples for biopsy were transported in Stuarts transport medium and sent to histopathology lab and report was considered as positive in case of identification of Helicobacter pylori infection by gram staining method. 
Version 25 of Statistical package for social sciences SPSS was used for data analysis. Mean and SD were analyzed for numerical data like age and frequency percentages were calculated for categorical data. Test of significance (chi-square test) was applied to see association among study variables. A probability value ( $p$-value) $\leq 0.05$ was taken as significant statistically.

\section{RESULTS}

Total of 100 samples from patients were examined for infections of $H$. pylori out of them male $65(65 \%)$ and 35 (35\%) were female patients (figure1); over all 30 patients were shown positive for infection of $H$. pylori. Out of which, male $17(56.7 \%)$ and $13(43.3 \%)$ females were diagnosed with $H$. pylori positive. In our study sample there were more $H$. pylori positive males as compare to females.

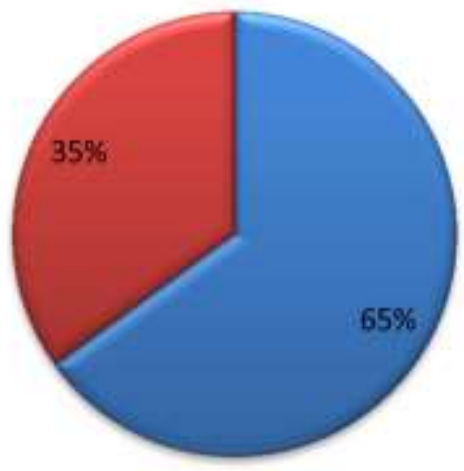

Male

a Female

Figure 1: Gender-wise distribution of subjects

The mean age of patients was $40.0 \pm 15.40$. Majority $H$. pylori positive patients were from age group between 40-60 years, from which $17(56.7 \%)$ of them were $H$. pylori positive; while $9(30 \%)$ of patients were from age between $20-40$ years of age and only $4(13.3 \%)$ were from age below 20 years of age as shown in figure 2 .

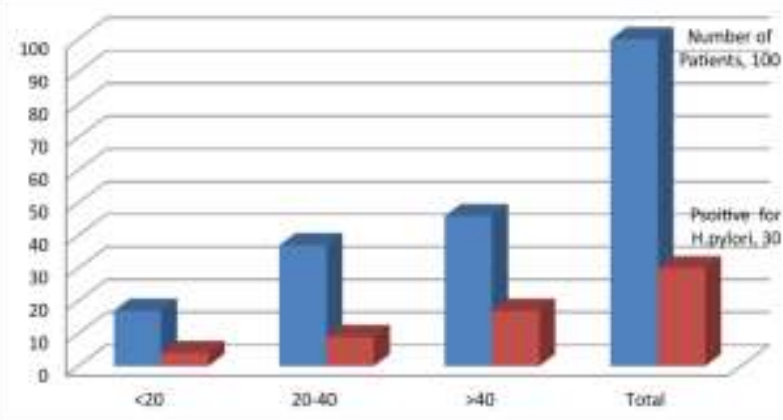

Figure 2: Age group of Patients and prevalence of $H$. pylori

Table 3: The gender according to helicobacter pylori infection

\begin{tabular}{|l|l|l|l|l|}
\hline \multicolumn{2}{|l|}{ Infection } & Gender & Female & Total \\
\cline { 3 - 5 } \multicolumn{2}{|l}{} & Male & 13 & 30 \\
H. & Positive & 17 & $(43.3 \%)$ & \\
\cline { 3 - 5 } & & $(56.7 \%)$ & 22 & 70 \\
& & 48 & $(62.8 \%)$ & \\
\hline Total & & 65 & 35 & 100 \\
\hline
\end{tabular}

\section{DISCUSSION}

The occurrence of $H$. pylori positive infection was $30 \%$ in our study; which is considerably lower in contrast to older studies. Results by Tahir et al.at the King Abdullah Teaching Hospital Mansehra for one year from May 2018 to April 2019.reported the prevalence of $H$. pylori as $56.4 \%{ }^{11}$.A study conducted by Qureshi et al among dyspeptic population from Nilore, Islamabad showed very high prevalence $(66.5 \%)$ of $H$. pylori infection ${ }^{12}$.A study from Tooba et al et at Liaquat National Hospital, Karachi reported $64.4 \%$ prevalence for $H$. pylori infection ${ }^{13}$

There is a high possibility that low rate of patients with $H$. pylori is probably due to increased administration of antibiotics, improved hygiene awareness and urbanization; also low number of patient turnover for treatment is also the contributing fact for such a low frequency of $H$. pylori positive cases. In the current study, the total frequency of $H$. pylori was comparable with the reported prevalence in countries of this region. A study from neighboring country Iran reported the frequency of $H$. pylori $23.2 \%$ was in their study ${ }^{14}$.

In our study $H$. pylori positive cases in males (17\%) were greater as compared to females (13\%). Similar outcomes were found in other studies done in Pakistan. Sarwar $\mathrm{N}$ et $\mathrm{al}^{15}$ in Lahore also confirmed similar findings that shown more infected patients in male gender as compare to female. Male gender predominance is also reported from all other studies carried out in different regions of Pakistan. Higher frequency of $H$. pylori cases in men are possibly due to contaminated food consumption, working in unsanitary conditions and the use of public toilets with poor sanitation.

Majority, $56 \%$ of $H$. pylori positive patients were from age group between 40 to 60 years of age. Our findings are in agreement with other similar studies done at both national and international hospitals. A research conducted in India found similar results where majority of $H$. pylori positive patients were from age of 40 years ${ }^{16}$. Similarly hospital in Karachi observed majority of middle aged patients infected with H.pylori ${ }^{17}$. Also from Barakaho, Islamabad also recorded increased risk of $H$. pylori infection with the advancement in age ${ }^{18}$.

Sarwar Net al. ${ }^{15}$ from Lahore also observed similar results. From above discussed results we can safely surmise that the younger population is less likely to get infected due to their better overall immunity and asymptomatic state of health. Reason for increased $H$. pylori infection in age 40 and above is due to following factors; such as exposure to contaminated environment, decreased natural immunity response due to other comorbidities and progressive age.

\section{CONCLUSION}

Near to fifty percent of our study population showed $H$. pylori-positive, and observed trend of $H$. pylori infection was found comparable to the recorded results also in available literature. Moreover, the studied population in the present study belong to a younger age group.

\section{REFERENCES}

1. EC S. Helicobacter pylori infection and treatment (Beyond the Basics) 2020 [Available from: 
https://www.uptodate.com/contents/helicobacter-pyloriinfection-and-treatment-beyond-the-basics.

2. Muhammad N, Afridi J, Mahmood N, Ali S. Frequency of Helicobacter pylori in Stool Specimens of Patients Suspected of Upper Gastrointestinal Symptoms in District Bunir. Jundishapur Journal of Microbiology. 2020;13(8):e1044.

3. Haq I, Muhammad A, Fazli Zahir MK, Anwar F, Akhtar MS, Ullah F. Serological and Epidemiology study of Helicobacter pylori infection among Dyspeptic patients in District Peshawar Pakistan. Adv Biores. 2020;11(3):81-5.

4. Kumar S, Metz DC, Ellenberg S, Kaplan DE, Goldberg DS. Risk factors and incidence of gastric cancer after detection of Helicobacter pylori infection: a large cohort study. Gastroenterology. 2020;158(3):527-36. e7.

5. Thrift AP, El-Serag HB. Burden of gastric cancer. Clin Gastroenterol Hepatol. 2020;18(3):534-42.

6. WHO. Biological agents. Volume $100 \mathrm{~B}$. A review of human carcinogens. IARC monographs on the evaluation of carcinogenic risks to humans/World Health Organization, International Agency for Research on Cancer. 2012;100 B:441.

7. Lee Y-C, Chiang T-H, Chou C-K, Tu Y-K, Liao W-C, Wu M$S$, et al. Association between Helicobacter pylori eradication and gastric cancer incidence: a systematic review and metaanalysis. Gastroenterology. 2016;150(5):1113-24. e5.

8. Kuo Y-T, Liou J-M, El-Omar EM, Wu J-Y, Leow AHR, Goh $\mathrm{KL}$, et al. Primary antibiotic resistance in Helicobacter pylori in the Asia-Pacific region: a systematic review and metaanalysis. The Lancet Gastroenterology \& Hepatology. 2017;2(10):707-15.

9. UpendraK S, Aman G, Arun G, Arati B. Role of helicobacter pylori in functional dyspepsia. Indian J Surg. 2004;66(6):3416.

10. Ji R, Wang P, Kou Gj, Zuo XL, Wang X, Li YQ. Impaired gastric mucosal integrity identified by confocal endomicroscopy in Helicobacter pylori-negative functional dyspepsia. Neurogastroenterol Motil. 2020;32(1):e13719.

11. Ullah T, Qasim Ml, Shah SFA. Prevalence of Helicobactor Pylori Infection in Patients with Dyspepsia. Medical Forum. 2020;31(1):21-24.

12. Qureshi T, Saleem K, Bilal R, Zafar S. General prevalence of Helicobacter pylori infection in dyspeptic population of Islamabad, Pakistan. The Nucleus. 2020;45(3-4):157-62.

13. Tooba AR, Nayab S,Awan KH, Awan FM. Frequency of helicobacter pylori in patients with functional dyspepsia. The Professional Medical Journal. 2019;26(8):1261-5. DOI: https://doi.org/10.29309/TPMJ/2019.26.08.3866

14. Kianmehr $M$, Zargar $M$, Hormati $A$, Fateh $R$, Nazari $R$. Prevalence of Helicobacter pylori and its cagA gene in patients with gastric cancer or peptic ulcer at an Iranian medical center. Novelty in Biomedicine. 2021 February 8;9(1):24-7. https://doi.org/10.22037/nbm.vi.32595

15. Sarwar N, Ahmed R, Saadullah M, ullah Khan K, Kamran S Baig FA, et al. Prevalence of Helicobacter pylori infection and its associated diseases in low socio-economic workers in tertiary care hospital of Lahore, Pakistan. Biomedical Letters. 2019;5(1):1-6.

16. Adlekha $\mathrm{S}$, Chadha $\mathrm{T}$, Krishnan $\mathrm{P}$, Sumangala $\mathrm{B}$. Prevalence of Helicobacter pylori infection among patients undergoing upper gastrointestinal endoscopy in a medical college hospital in Kerala, India. Annals of medical and health sciences research. 2013;3(4):559-63.

17. Awan RH, Nayab S, Awan KH, Awan FM. Frequency of helicobacter pylori in patients with functional dyspepsia. The Professional Medical Journal. 2019;26(08):1261-5.

18. Rasheed F, Ahmad T, Bilal R. Frequency of helicobacter pylori infection using 13C-UBT in asymptomatic individuals of Barakaho, Islamabad, Pakistan. Journal of the College of Physicians and Surgeons Pakistan 2011, Vol. 21 (6): 379-81 